\title{
Redefining Boundaries? The Case of South Asian Muslims in Paris' quartier indien
}

\section{Miniya Chatterji}

\section{OpenEdition}

\section{Journals}

\section{Electronic version}

URL: http://journals.openedition.org/samaj/119

DOI: $10.4000 /$ samaj. 119

ISSN: $1960-6060$

\section{Publisher}

Association pour la recherche sur l'Asie du Sud (ARAS)

\section{Electronic reference}

Miniya Chatterji, «Redefining Boundaries? The Case of South Asian Muslims in Paris' quartier indien », South Asia Multidisciplinary Academic Journal [Online], 1 | 2007, Online since 14 October 2007, connection on 01 May 2019. URL : http://journals.openedition.org/samaj/119; DOI : 10.4000/ samaj. 119

This text was automatically generated on 1 May 2019.

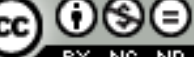

This work is licensed under a Creative Commons Attribution-NonCommercial-NoDerivatives 4.0 International License. 


\title{
Redefining Boundaries? The Case of South Asian Muslims in Paris' quartier indien
}

\author{
Miniya Chatterji
}

1 It is an interesting 'double paradox': globalization creates free movement of capital in the face of international events increasingly attempting to control movement of labour. Yet the shifts in the demographic patterns in most parts of the world today are clearly more than ever before. Cities like New York, London, Rome, Paris clearly manifest their increasing diversity in the colour, race, language of their migrant population which currently hence comprise of large numbers of illegal entrants making a living out of doing odd jobs. Now, a myopic investigation of the societal effects of this phenomenon reveals changes not just in the host environs but also in the internal structure within these migrant communities. Within the community, there is a change in how members relate to one another, in their criteria for the acceptance of the 'other' in their newfound groups, and in this way in their definition of community boundaries. This paper takes the case of the South Asian Muslim quartier in Paris, as a means to illustrate a larger sociological phenomenon of change in the internal structures of small economic migrant groups in multicultural cities today. ${ }^{1}$

2 The 'community' has of course for long been the subject of attention for sociologists and anthropologists alike. A community, for structuralist Talcott Parsons, ${ }^{2}$ denoted a wideranging relationship of solidarity over a rather undefined area of life and interests. For conservative sociologist Robert Nisbet, ${ }^{3}$ it was a continuation of the concern with loss of community as central to $19^{\text {th }}$ century sociology where there was a fear that these features were disappearing in the transition from a rural-based to an urban-industrial society.

This alleged loss of community was in fact much earlier itself central to the work of German sociologist Ferdinand Tonnies, who often described as the founder of the theory of community, in his book Gemeinschaft and Gesellschaft (Tonnies 1957) presented idealtypical images of forms of social association, contrasting the 'solidaristic' nature of social relations in the former, with the large-scale and impersonal relations thought to 
characterize industrializing societies. The sociological content of community still remains a matter of debate. However, it is viewed in this paper simply as a particularly constituted set of social relationships based on a 'commonality' shared between its members-this commonality often being a/several particular or overlapping strands of identity composites which run through all members.

The present study examines the implications of the transposition of intimate social bonds between Muslims living in South Asia to when these South Asian Muslims migrate to Paris. The arguments in this study would be brought out through the application of Putnam's conceptual tools of 'bonding' and 'bridging'. Putnam says that 'bonds' are intrusive, inward looking and tend to reinforce exclusive identities and homogenous groups. For example ethnic organizations. On the other hand, 'bridging' relations are outward looking and encompass people across diverse social cleavages in links between members of the group. Examples of bridging social capital include the civil rights movement, many youth service groups, and ecumenical religious organizations (Putnam 2000: 23). By these definitions, the Indians, Pakistanis and Bangladeshis in their host country would group themselves according to a particular or a composite of common 'bonds'. These common bonds could be that of a same country of origin, language, religion, etc. 'Sub-groups' would be formed by migrants sharing the same bonds. These sub-groups would be migrants grouping along national lines (e.g. a 'Pakistani' group), linguistic lines (e.g. a group where members all speak the Bengali language), sectarian lines (e.g. a group where all members belong to the Sunni sect), etc.' Migrants could also internally form group structures based on common 'bridges' which they build amongst themselves. For example, Sunnis and Shias from South Asia could 'bridge' together and form a group defined by the common religion of Islam as a whole. Else, the migrants might even build new linkages that would bridge them across different existing 'bonds'.

Now going by our definition of 'community' earlier, these 'groups', formed by either common bonds or bridges, are essentially grouping according to common traits. Then are these groups 'communities'? Can communities only be defined by traits that bound them together in their country of origin (e.g. language, region of origin, etc)? Within this larger group of Muslim migrants from the Subcontinent, can we then define 'communities'?

\section{South Asian migration to France and Paris's quartier indien}

6 This paper results from a questionnaire type survey conducted by the author in year 2004, of a sample of 120 migrants in the quartier indien of Paris. This exercise was accompanied by an additional participative approach that covered 30 South Asian Muslim migrants in Paris (in and also out of the quartier indien). The quartier indien located in the northern stretch of Paris's zone one, mainly comprises of Rue Faubourg Saint Denis, Boulevard Strasbourg, Rue de la Fidélité, Rue Jarry, Passage Prado and Passage Brady. Yet, ironically, it composes of a population holding a majority of non-Indians (Pakistanis, Bangladeshis, Sri Lankans and Mauritians), a large number of non-Hindus, and who are non-Hindi speaking. A large number of Buddhist Sri-Lankans, Pakistani, Bangladeshi (and also Indian) Muslims are found in the quartier, speaking mostly Punjabi, Urdu, Bengali, Tamil and Singhalese. 
7 France has about 60,000 Indians, 50,000 Pakistanis and 16,000 Bangladeshis, ${ }^{4}$ according to the Indian Embassy in France. Most of this population live in Paris and its outskirts. Amongst this group, the first South Asians to come to Paris were from Pondicherry in the 1950s. Gradually the 1970s saw a trickle from the Tamils of South India who joined the Sri Lankans and set up shops in the area stretching from Gare du Nord up till La Chapelle. The 1970s also saw the Pakistanis set up their restaurants at Passage Brady (on Rue du Faubourg Saint Denis). Indians soon joined them there in the restaurant business. The 1980s saw a timid inflow of Indians who opened DVD shops, sari stores and worked alongside the Pakistanis in grocery shops. Towards the end of the 1980s there was an increase in the number of Bangladeshis in the form of refuges or even illegal migrants. In the 1990s, the business of telephone cards, bookshops, cheap hair cutting saloons for men, developed at Rue Jarry and the adjoining lanes of Rue de la Fidélité.

The recent years have witnessed an increasing number of illegal migrants and asylum seekers of South Asian origin. There are no official accurate figures, but estimates say up to 20,000 illegal migrants from India are landing in the EU each month. According to an Indian news website which had a special report on 'Paris teems with Indian illegals':

With the visa regulations for the United States-a migrant's dream-tightening each year, the migrants are now looking for other pastures... Once inside the EU borders and free from immigration controls, the illegal migrants then look for their ultimate destinations-with Paris and Frankfurt emerging at the top of their list' (Nayar 2005).

9 Also for example, according to reports at the Office Français de Protection des Réfugiés et Apatrides (OFPRA), the number of Indians in France who demanded asylum, increased by almost $100 \%$ in 2004.

Illegal migration has consequential social effects that have often been the cause of much concern for French authorities. For example, in the case of Passage Brady restaurant workers there are a large number who marry goris (white women) or at least confess to have no reservations in doing so. This is perhaps explained by the fact that the restaurant business was an early economic activity initiated by the South Asians in Paris. In the 1980s, when the trickle of migrants from South Asia began, a large number were illegal and entered without papers of stay permit or worked without work permit. The restaurant business being one of the early means of South Asian employment to be established in Paris, most of these illegal workers worked here. Soon the French authorities discovered this, and targeted these restaurants for tighter check on the legal status of their workers, conducted frequent surprise raids in these restaurants, and pressed restaurant owners to regularize the situation. Passage Brady at that time, a budding centre point of South Asian cuisine in Paris, and a shelter to a large number of illegal workers, was an area especially targeted by the French authorities. To this day, restaurant workers and especially those in Passage Brady are most pressed to have their working papers right. This pressure also results in a large number of mariages blancs (false marriages), that is marriages primarily for gaining naturalization and hence legal papers to stay in France and permission to work legally. Muzaffar Hussain, doorman at a restaurant at Passage Brady, says, 'I married a French woman and took divorce a few months after that. Here in Paris, you have to do like this. No, but if I have a daughter, I will get her married to a Muslim from Pakistan. ${ }^{5}$ But the trends are also changing: restaurant workers out of pressurizing necessity of having legal papers to work, initially married French women, the trend now shifting towards marrying a woman of a minority 
community, who has already been granted a French citizenship-Madagascar and Mauritian women (usually of Indian origin) being a current popular choice. Bangladeshi women are also a popular choice, the prime reason here being poverty for women who have turned mariage blanc into a business.

Further it was found that it was the host society in Paris who attributed the name quartier indien, to that particular zone. This was in the 1980s, when it became a budding zone of commerce run by the pioneering South Asian migrants in Paris. Says Fida Hussain, owner of 'Fleurist' at Gare de l'Est, who came to Paris from Pakistan in 1974:

When us Pakistanis and Indians started working here, these French said it was the 'quartier indien'(...) they like calling us like that (...) they have 'quartier chinois', 'quartier latin (sic)', and now 'quartier indien' (...) the Chinese, the Spanish (sic) never named themselves like that, and nor did we from Pakistan, but all Indians even Pakistanis and Bangladeshis want to work now in quartier indien.

The host society perhaps played an important role in 'identity labelling' at an early stage of settlement of this community? The community at that time being a recent one cashed in on this identity 'granted' by the host society. It could be interesting to draw parallels with sociologists Vuddamalay and Khelifa's work on the Goutte d'Or region in Paris which present an identical situation to the quartier indien (Khelifa 1979, Toubon \& Khelifa 1990). 'In fact, (...) it is through its commercial role (attributed) to the immigrant community of Paris that the Goutte d'Or has achieved its current reputation' (Vuddamalay 1985: 64).

The quartier indien in Paris then even today is the 'trade zones' populated by South Asians in Paris-and not where the South Asian Muslims 'live' (nor is it the area of cultural, traditional, recreational interaction between them). This observation should also be an indication of the importance of economic activity for the community in question, since work related organizations are the 'locus of social solidarity, a mechanism for mutual assistance and shared expertise'(Putnam 2000: 151). And even though 'solidarity is a crucial precondition for economic collaboration' (Putnam 2000: 151), within this seeming solidarity of a consolidated unique South Asian migrant group in the quartier, there exist in reality various sub-groups within it. This, like the apparent general image of Vuddamalay's Goutte d'Or, 'as a North African quarter (that) misrepresents the much more complex intermixture of ethnicities actually present'.

\section{Shifting community boundaries}

The present paper attempts to identify these 'sub-groups' by tracing out the nature as well as the depth of bonds and bridges amongst the members of the South Asian community in Paris' quartier indien. Essentially the paper would examine to what extent can these sub-groups be defined as 'communities'. But to do so, it would be necessary to first etch out the factors that determine these bonds and bridges between them. And then what is the composition of factors that place an individual 'in' or 'out' (or on the fringe) of a particular group? This would essentially mean tracing group boundaries.

A migrant's country of origin is usually a potential bonding factor with his fellow countrymen. In the case of Paris' quartier indien, Indian Muslims held least bonding between them especially as compared to their Pakistani and Bangladeshi fellow migrants. A significant number of Indians in the quartier in fact shared very close relations with Pakistanis in the area. This could be because of the dichotomy of identity strands of religion vs nationality that reduces the nationalism quotient amongst Indian Muslims. 
For an Indian Muslim for example, Islam has larger cultural connotations than religious (he often does not feel part of global Islamic networks) or national (Pakistan and Bangladesh unlike India are Muslim countries). Indian Muslims therefore find themselves bound to Pakistani Muslims who share the same South Asian 'cultural' components of Islam. Nationality then takes a backseat. Pakistanis on the other hand evidently have strong bonds between them as they share religious (even though members might have different sects), national, cultural bonds (even though migrants from different regions in Pakistan would have specific cultural practices) amongst their fellow countrymen in Paris. Bangladeshis on the other hand tend to restrict themselves to relations with only their own countrymen, but the reason for them doing so is more due to linguistic and economic factors rather than nationalism.

Obviously enough, the belonging to a given locality can generate a strong bond among migrants, this being particularly true in the case of Pakistanis. (It can therefore be regarded as a bond created by the migrants, in the host country). For example, a Pakistani building painter Mohammad Changez claimed to know the presence of 3,000 to 5,000 Muslims from Rawalpindi. While Mohammad Sayeed admitted to know 250 Muslims from one (his own) district of Rawalpindi-of which 20 lived in the same building. Chain migration clearly seemed to be the principal catalyst of this phenomenon.

There is marked language erosion in the mother tongue (or regional/national languages) amongst the South Asian Muslims in the quartier indien. This language erosion was observed to be a deterrent in creation of bonds. It weakens bonds between migrants originating from the same region or city of origin. All members of the sample confessed to speak most in Paris, a language other than their own dialect. This is only evidence of the intermixing of the different 'sub-groups', as preservation of language is a sign of 'pure' ethnic groups. If Indians were to mix only with Indians, then perhaps only Urdu would prevail amongst members of the group. This does not seem the case amongst South Asians in Paris. The language that most Muslim migrants from all regions of India and Pakistan (not Bangladeshis) have adopted is Punjabi, Urdu and a hybrid language of French, Urdu and Punjabi. It should well be noted that Bangladeshis persevere with Bengali (the erstwhile linguistic nationalism in Bangladesh which transposes itself in Paris? See Murshid 1993), creating a rather closed group with rare outward communication channels.

Bonding by a shared religion is often a potential factor of strong communitarian feelings, more so amongst migrants. Firstly, the sample clearly demonstrated a preference of criteria of region of origin over religion. The group did not exhibit any strong bonding with Muslims not originating from South Asia. It was observed that Islam for these South Asians, even in dar-al-harb Paris, did not constitute a principal bonding factor. On the other hand, South Asian Muslims were mostly open to interaction even with South Asians who are not Muslims in Paris, but not surprisingly were far stricter in their relationship with South Asian Hindus over the question of marriage. Marriage, the highest level of bridging frontier, was declared by a significant majority in the sample, to be preferred with only a Muslim-mostly precising a preference for a Muslim from the individual's country of origin, again a large majority preferring a transnational marriage with someone from their own country. This is where Islam is important for them. Pakistanis, following the tradition of cousin marriage in their country of origin, mostly preferred a partner from their own family. Ali, an 18-year old third generation Pakistani living in Sarcelles, whose only interaction being with Arabs and French in Paris, was engaged a 
year back to a cousin from the city of origin of his parents in Pakistan-a match arranged by his parents to which he gave his consent. ${ }^{6}$ The reason given by most was 'the preservation of one's culture and tradition'. Culture, essentially a component of religion, holds more significance for South Asian Muslims than religion per se. This is most evident in criteria for marriage. Hence, culture and tradition, of which more specifically language and the continuity of knowledge of the correct rites during religious ceremonies is an important criteria for South Asian Muslims in Paris. They would prefer a marriage partner to be Muslim because a Muslim spouse would increase family prestige, fortify family ties and build greater transnational links. They prefer traditional arranged marriage systems and even cousin marriage, not purely due to religious reasons, but to ensure continuity of 'culture'. Often, the dream of marrying a 'good Musalman' with all the virtues that the Quran prescribes, lies only low in their marriage preferences. Thus, it is clearly not religious bonding per se but 'South Asian Muslim culture' amongst the South Asians Muslims in Paris which explains their marriage preference with Muslim partners.

Now there is another factor of influence to consider: 'Arab' Islam. The majority of Muslims in Paris being of Arab or African origin, and France's historical links with the Arab and African countries from where these Muslim migrants in Paris come from, the host society attributes an image to 'Islam in France' (an image of 'being Muslim' which is very different to the South Asian Muslim). Hinduism in India has had a strong influence on South Asian Islam, thus popularizing cults like Sufism, song, dance and other cultural forms, affecting ceremonies of marriage and celebration, and finally the attribution of significance to rites and rituals. When faced with a majority of Muslims to which South Asian Muslims cannot relate themselves to, and a host society which has had a history of understanding 'this Islam' which South Asian Muslims cannot identify themselves with, the South Asian Muslims tend to downplay their religious sentiment, at least in the public sphere.

But perhaps this is a case only in the present early migrant generation, because there are instances where Arab Islam does have its influence on the minority South Asian Muslims. This influence could grow with the coming generations to merge the two together. A clear example of this was Sahera Sayeed, a 13-year old Pakistani third generation school girl, born in Paris, has all Arab and French friends at school, lives in Sarcelles amongst an Arab community. She started wearing a headscarf (in the Arab fashion) whereas her mother does not and never did. Sehera's mother-Shehnaz Begum, a second generation South Asian Muslim has never stepped out of Sarcelles since her arrival from Rawalpindi to Paris in 1980 after her arranged marriage to a Pakistani cousin originating from Rawalpindi living in Sarcelles. She persists on her daughter's marriage with a Pakistani Muslim cousin from Rawalpindi, not because of religion but 'tradition'. But at the same time, she did not mind her daughter wearing the foulard (headscarf) in the Arab fashion as 'One should wear foulard because it is our own identity'.

21 Now, the only case where religion bridges frontiers between countries of origin is in the case of housing. The South Asian community being a recent one, not many South Asians in Paris are house owners to be able to rent out their houses to newer South Asian migrants. The South Asians in Paris are not in a position to find a solution to the housing problem from within their community. To rent an apartment or studio, a French propriétaire (house owner) asks for legal documents, a carte de séjour (stay permit). The sample unanimously declared that French house owners are skeptical about renting out 
an apartment to a brown-skinned, uncouth South Asian. Rents are high. Most French landlords do not approve of the common practice amongst South Asians to live together in groups ranging from 5 to 20 in a studio or apartment. Out of these 5 to 20 at least one would have legal papers-it is he who signs the lease or contract of the house, while the others live with him: this is clearly not acceptable by most French house owners. French house owners posing problems, the South Asians turn towards Arabs and Africans, minority communities in Paris who are better settled and have a longer history in Paris than the South Asians. Here the South Asian Muslims play the 'Muslim card'. Says a Pakistani rose seller, 'They (Africans, Arabs) are also Muslims. They understand us, we are brothers. We tell them that. We tell them to rent their studio to us. They do it. If one Muslim doesn't help another Muslim, then who else will?' Contrary to the low affinity of Muslims from South Asia towards Arab and African Muslims, housing used the bonds of religion to bridge the frontier of difference in countries of origin. But this will pass, because it was observed that more and more South Asian Muslims are now overcoming this problem by trying to buy houses on 'Kreydee' (credit).

Religion not playing a significant role in bonding amongst South Asians, it was also observed that the difference between the sects 'shia' and 'sunni' was blurred amongst them except in the case for marriage. Both groups interacted with one another and did not discriminate. For example, most were not aware of the sect of their co-workers at work. When asked if they had friends from the opposite sect, most answered enthusiastically in the affirmative. The only South Asians who seemed less enthusiastic (though they all claimed good relations with the opposite sect) were those who have been living in Paris for longer periods of time. It is well known that migrants living outside their country of origin for longer periods of time tend to overemphasize the cultural and religious practices of the country of origin. This is usually due to the fear of losing contact with traditions and not being able to pass them on to future generations. For the rest of the recently arrived South Asian Muslim migrants, faced with the co-existence of this large looming 'other' i.e. the Arab Muslim group in such close proximity, many religious differences amongst themselves get blurred. ${ }^{7}$ The shia-sunni divide here is one such case. However, there still existed some discrimination against Ahmadiyyas being considered as non-Muslims without doubt. On the other hand, a popular response to them being Deobandi or Barelwi, met with an answer either 'What is that?' or 'No, I am Sunni'. A demonstration of the fact that the frontier of difference in religious school of thought is not an issue, as a large majority in the sample seemed ignorant of the mere existence or the difference between the Deobandi and Barelwi school of Islamic thought. ${ }^{8}$

There are, as this paper has so far demonstrated in the case of the South Asian Muslims in Paris, newer forms of relations taking shape between these recently arrived economic migrant groups. There is a change in the definition of group boundaries, due to the changing criteria of acceptance of an individual to a group (each of which are nothing but subsets of the larger South Asian Muslim community). As boundaries shift and move, there is the development of new groups sharing certain commonalities amongst them. Going back to our definition of 'community' at the start of this paper, could we then infer that each of these 'groups' whose members share these new combination (vis-à-vis the combination of traits that defined 'communities' in their country of origin) of bonds and bridges are indeed forming different communities in their host country? 


\section{The prevalence of economic activity in community definition}

24 Now, to examine this hypothesis, a study of the bonds and bridges shared by South Asian migrants showed that there was an overlapping of several linkages (both bonds and bridges) in members of the same economic activity. South Asian Muslims in Paris who shared the same economic activity, also shared amongst themselves several other common linkages too. Does this differentiate them as specific small communities within which members share a similar world-view? Would this mean that the definition of community for the group in question in Paris tended to revolve around the sharing of economic activity of its members? Has 'community' in Paris' quartier indien come to be defined not so much by country of origin, nor religion, nor language, but by the profession or economic activity of the migrant?

For example painters or other construction workers in buildings mostly confessed to have good relations with individuals originating from all countries. So in this way, yet all except 2 of the 30 cases of painters in the sample happened to be Pakistani, working with Pakistani fellow-painters, their contractor also being Pakistani. Pakistanis newly entering Paris join the painting profession because of the low levels of skills required for the work, non-institutional hence easy entry into the profession, but primarily due to the large number of their countrymen being involved already in this profession which gives them communitarian support. Similarly most Bangladeshis flock together as rose sellers. Most of the telephone card sellers consist of Pakistanis and Indians. Within this group, there is a bridging of relations across Pakistanis and Indians. Employees at restaurants are a mix of Indians, Pakistanis and Bangladeshis who were bonded together as 'South Asians' against the French. This again can be explained through the nature of their profession, where the restaurant team including the restaurant owner, managers, cooks, receptionists, cleaners and even the interior decorators mostly belong either to India, Pakistan or Bangladesh, while the clientele is most frequently French.

Migrants engaged in each economic activity also share linguistic practices. Telephone card sellers are the most multilingual as they are conversant in different South Asian languages. They also usually speak a spattering of French. According to Qamar who runs a telephone card shop at Gare du Nord:

We have all kinds of customers. Indian, Gujarati, Pakistani, Tamil, Bangladeshi, African, Arab, Latin American (...) I speak a few sentences each of all languages here at the counter...Hindi, Marathi, Punjabi, Urdu, French, English of course and little bit of Spanish (...). But what language do I speak with Africans or Sri Lankans? I speak French with them.

Contrary to popular belief, restaurant workers do not speak French. They mostly 'understand' key French phrases that clients use; they know the French equivalent words of the menu served and can speak a few classic phrases and responses. Mostly speaking Punjabi at work, as most communication is amongst colleagues and not clients, this unique linguistic pattern of restaurant workers is coupled with a construction of a unique jargon: 'Koozy' for cuisine, 'mito' for mi-temps, 'playto' for plein-temps, and the universal 'puttroh' for patron and 'tranjey' for étranger, 'public-city' for publicité. Rose sellers on the roads are linguistically the most stable. Apart from their select jargon like 'lizy' for Champs-Elysées, 'tuwor' for the Eiffel Tower, 'bara gate' for Arc de Triomphe, they also know 
by rote a few key sentences in several European languages to attract tourists. Secondly, a large number being Bengalis, they continue to speak Bengali else the few who are not Bangladeshi speak in Punjabi or in their own indigenous language of country of origin hence mostly not attempting to learn the French language. At times individual actors play an important role in linguistic bonding. For example there is a bridging between Indian Bengalis (even if Hindu) and Bangladeshis (majority being Muslim) in Paris. The Maison de l'Inde (India House) at Cité Universitaire (University Campus) in Paris has been bringing together since the year B.C. Sanyal, an Indian Hindu Bengali took charge as the Director in January 1, 2000, Indian Bengalis and Bangladeshis together for various cultural programmes. In fact, even 'Bangladesh Day' was celebrated at the Maison de l'Inde in the years 2003 and 2004. A strong reason being the caretaker of the India House is a Bangladeshi Muslim (and is a freelance magician).

Migrants engaged in the same economic activity also shared similar religious practices (indeed not always synonymous to 'religious beliefs'). As the following examples show, this is a direct consequence of the particularities of the timings and work environment that each profession demanded. Restaurant work hours are from 10 a.m. to 11.30 p.m., with many giving a break between 3 p.m. to 6 p.m. The work hours and the demands of continuous client service, is not compatible with the five daily prayers at the mosque, elsewhere or in the restaurant itself. They do not do so even during the mid-day break, preferring to play cricket instead. Painters and construction workers work from 8 a.m. to 5 p.m., in an outdoor environment which is not conducive to following the rites preceding the namaz, nor the reading of the namaz in an appropriate manner. Their workplace changes according to the contract and project, which is very rarely located in central Paris, and usually in the banlieue (peripheric zones of Paris). This hampers their chances of visiting the mosque. Telephone card shops in Paris (unlike in London) are built in a counter-window cubicle fashion. The seller sits in his cubicle behind which there is a large room, where there might be other co-workers managing accounts. The client is faced from a small-glassed window with a slit at the bottom to receive money and give the card. This set up and the presence of co-workers makes it convenient for telephone card sellers to either shut the counter or ask his co-worker to replace him for a few minutes, while he reads the namaz. However, visiting the mosque is not always possible, and is restricted to mostly once a week. On the other hand, small grocery shops that are run by the person who owns it usually closes shop for a few minutes during prayer time. Rose sellers on the other hand work only from 6 p.m. to 11.30 p.m. In spite of having substantial amount of time on hand, only a few rose sellers, it was observed, do read the daily prayers, but a large number of rose sellers are the most frequent visitors to the mosque.

The structure of the profession also determines the nature of relationship with colleagues. Rose sellers work independently and buy their roses from either Rungis, a wholesale depot near Paris Orly airport which has frequent police raids for legal documents. So those who have an illegal status buy their flowers from discreet flower shops like that at Rue du Faubourg St Martin, owned by Fida Hussain, who came to Paris in 1974 from Pakistan. Rose sellers being independent workers, have a relationship which does not require professional coordination which further leads to an absence of knowledge of each others way of doing things. For example, none of the rose sellers were able to tell where his colleague usually sells his roses. Painters are independently employed by a contractor, yet coordinate amongst themselves to work on projects, 
breaking away in groups to work with different contractors, and are usually familiar with most professional moves of their colleagues of the profession. DVD sellers interact with each other with a sense of competition to bring to Paris the latest Bollywood films, and also share their wares amongst themselves. However the telephone card sellers are organized in a structure akin to that of a corporate. Telephone card enterprises consist of sales outlets (numbers varying from 1 to 20 all over Paris), a network of direct distributors (10 to 100), indirect distributors (100 to 5,000), a head office, administration staff and accounts staff. In this structure, the relationship between employees was found to be professional, diplomatic and which do not 'mix work with pleasure'-the principle reason for a conscious distance maintained amongst each other. On the contrary, restaurant workers need to co-ordinate and interact with colleagues of their restaurant, and also with other restaurants in that area, and elsewhere: not apparent to the client, most food items on the menu are brought in from other neighbouring restaurants. Restaurants of different names are dispersed all over the city and yet they are owned by the same person.

These new definitions of boundaries are significant to the host country as well in forming the socio-political transnational linkages with the country of origin. For example, each of these economic groups manifests a particular political sensibility. Restaurant workers were found to be the most politically mobilized. Bearers of direct impact of employment and legal policies and high levels of interaction with both South Asian and non-Asian people, result in an initiative to learn more about the host country. Their valid legal status encourages them to participate in manifestations and if possible (in the future for those who cannot do so at the moment) cast their vote in French elections. A fairly popular response to their opinion about the French government relations with Muslims in France was that 'The French government is good. We Muslims create our own problems'.

31 On the contrary, rose sellers due to their often illegal status in Paris do not visit their country of origin. In spite of this, it was found that the knowledge and levels of mobilization amongst the rose sellers towards their home country was very high. Abundance of free time provides time for discussions and exchange of news about South Asian politics. This means that the source of their knowledge of their home country was mostly through word of mouth. Other than this, most rose sellers not being able to speak or read French, few also bought newspapers in their own vernacular language, reading news about their country of origin. These newspapers once again focus on South Asian news. This common source of political knowledge shapes common political notions. The absence of news sources on France result in the fact that rose sellers are not well aware of French political affairs, neither do they know the existence of concepts such as secularism and democracy. When questioned about their perception of French politics, rarely did any rose seller have an opinion to offer. This shows low interest levels towards French politics. In contrast, enthusiastic detailed opinions (and even much criticism) of Bangladesh were common amongst Bangladeshi rose sellers.

Painters on the other hand, had the strongest links with their country of origin, and its political and social affairs. This was mostly due to close interaction amongst these South Asian workers during work hours and also after work hours (these construction workers maintain very high levels of social relations with their fellow workers even after work hours). In fact, most of the workers being from Pakistan, the bond of common country of origin becomes stronger for them. Their discussions on Pakistani politics make a large 
chunk of their conversations amongst themselves. The other important aspect is that building painters work on construction sites on the peripheries of the city. This excludes them from much of the local news in Paris. Further, the physical 'exclusion' that the profession brings about also excludes them in spirit from French political and social affairs. Paradoxically, all painters however agreed unanimously to react and manifest against a French government policy they would be opposed to. This fact seemed to emanate not so much from their interest in French politics, but from a feeling of being the 'other' which exclusion (in mind and body) from French society perhaps brought about.

Small shopkeepers however were closer in their definition of secularism to as it is perceived in France. This showed that not only were they aware of political 'events' in their host country, but they also understood the social and political framework they were living in here. The reasons for their perceptions seemed to be directly linked to the frequency of contact with their French and multiethnic clients in Paris. Moreover they sell newspapers (local news, French national newspapers, international newspapers in English) and watch television all day in their shops when not entertaining clients. Very little of their knowledge emanates from 'word of mouth' and discussions as is in the case of rose sellers or to an extent in the case of construction site painters. Shopkeepers also interact with wholesale suppliers (not always South Asian), middlemen, French customsthis develops their awareness of the 'French' way of doing things. They were in fact motivated to participate in French society and politics, at the same time also had good levels of knowledge of current political and social affairs of their country of origin. There were three reasons identified. Firstly, South Asian grocery stores sell newspapers in vernacular South Asian languages which mostly contain news about the country of origin; secondly it is a common practice in most South Asian small shops in Paris to have a television placed for the entertainment of the shopkeeper which once again have only South Asian channels running; thirdly, interaction with a large number and variety of people (as clients and collaborators) opens their minds to participate in the French society-and not remaining restricted to only colleagues at work.

Telephone card sellers in the sample were found to be the most disinterested in politics. Economically and professionally driven, these members of the sample restricted their domain of interest to the telephone card industry. These telephone shops receive large numbers of clients (far larger in number that the small shopkeepers). They therefore do not have time to interact much amongst themselves during work hours. The 'professional' structure of social relations at the work place does not encourage much interaction amongst employees after work hours. For example, the employees at telephone card shops had very low levels of bonding amongst work colleagues. This has important consequences as these shops have long working hours (usually from 9 a.m. to 10 p.m.). So the impact is for long periods of time in the day. The ambience at the telephone card shops develops some common behaviour patterns of mental preoccupation with work, entrepreneurship, and low levels of social life. This also brought low levels of interest and time to politics of home country and host country.

But the South Asian Muslim community in Paris is a case that presents a range of different categories of boundaries-a range which is comparatively far broader than the dominant migrant group of North African Muslims (certainly not undermining heterogeneity within the North African group either) in Paris whose sub-groups at least share race, religion and region. Amongst the South Asians in Paris the boundaries are 
much more varied: boundaries of language, class, caste, sect, regional, ideological, some historically determined, and others locally evolving continuously. Not many of the boundaries coincide with each other, and therefore there is not any kind of mutual boundary reinforcement. The boundaries are mobile. They cut across each other, and sometimes certain boundaries do bundle together (like the case of economic activity bunching together with some other boundaries), but not making the end result strong enough to create a definite rift.

\section{Conclusion}

However there could be three hypotheses that could mark the future trends of the fate of this recent migrant group of South Asian Muslims in Paris. Firstly, it could be that the present situation is simply a typical case of 'pioneering bachelor' phase (Ballard 1996) of recent economic migration. This would mean that this phase would pass in some years, with the arrival of more women and children, the life of this migrant community would begin to revolve around socio-cultural adaptation (or issues of non-adaptation) to its host society, and boundary reinforcement would begin along lines other than mere economic activity. The second hypothesis could be that 'economic activity' remains as a characteristic defining boundary of internal group structures for the South Asian Muslim migrants in Paris. Then the 'economic activity' could act as an intermediary level thus serving as a cushioning for raw communitarian bonding to reshape themselves before they affect the political domain directly. The bonds in this case need to be kept mobile, juxtaposing and intersecting-but never coinciding. The increase of energy in the local economic quartier will help lessen the emphasis to be laid on the ghettoization of habitation. The third hypothesis is that 'economic activity' will cease to be a meeting point of intra-group structurations and political mobilizations. This discontinuation could be due to the fact that the grouping by economic activity is just a 'phase' in the migratory trends of this community in Paris. There is high probability that economic activity is of high significance now because of the 'need' for this 'pioneering' migrant group in Paris to first and foremost settle down. Once they do so, perhaps their attention shall turn to more socio-cultural issues-and finally it would do well to remember that after all it was in Rue Jarry of the quartier indien that the South Asian Muslims of Paris manifested against the Rushdie affaire in London way back in 1989. In contrast, there was no reaction from them against 'l'affaire du voile'. An indication of a very strong South Asian transnational and diasporic bridging? Is it then a 'South Asianism' which even wins over religious bonding? Only time will tell.

\section{BIBLIOGRAPHY}

Ballard, Roger (ed.) (1996) Desh Pardesh: The South Asian Presence in Britain, London: Hurst. Le guide de l'entrée et du séjour des étrangers en France (1995), La Découverte/Guides GISTI, Paris: GISTI. 
Kepel, Gilles (1994) A l'ouest d'Allah, Paris: Seuil.

Khelifa, Messamah (1979) 'La Goutte d'Or', in Hommes et Migrations, 970, Paris: ADRI, pp. 19-25.

Murshid, Tazeen (1993) 'Bangladesh: The Challenge of Democracy-Language, Culture and

Political Identity', Contemporary South Asia, 2(1), Cambridge: Carfax, pp. 67-73.

Nayar, Ranvir (2005) 'Paris Teems with Indian Illegals', The Rediff Special, February,

www.rediff.com.

Nisbet, Robert (1953) The Quest for Community, Oxford: Oxford University Press.

Putnam, Robert (2000) Bowling Alone: The Collapse and Revival of American Community, New York: Simon \& Schuster.

Tönnies, Ferdinand (1957) Community and Society (Gemeinschaft and Gesellschaft, 1887),

translated and edited by Charles P. Loomis, MI: Michigan State University Press.

Toubon, Jean-Claude ; Khelifa, Messamah (1990) Centralité immigrée: le quartier de la Goutte d'Or, Paris: Collection Recherches Universitaires et Migrations.

Vuddamalay, Vasoodevan (1985) La Goutte d'Or: un pôle commercial immigré, Mémoire de 1'Institut d'urbanisme de Créteil.

\section{NOTES}

1. This paper is based on some results from a research treating a sample of 150 interviews of Paris' quartier indien South Asian Muslims, conducted by the author in 2004-2005.

2. One of Parsons' concerns, within his general sociology, was to understand the relationship between social structures (how societies are institutionally organized) and social actions (the range of behavioural choices individuals believe are open to them). His basic argument, in common with all structuralist sociology, is that the former condition the way the latter develop in society.

3. The Quest for Community was a clarion call about the dangers of centralization of power and the threat it posed to American society. Nisbet's predicted the growth of crime, illegitimacy, drug abuse, poverty and illiteracy which would result from the continued marginalization of traditional local associations. This is the strand of thought which later liberal communitarianists like Michael Sandel and Robert Putnam built on. See Robert Nisbet 1953.

4. Indian Embassy in France.

5. France allows the granting of citizenship of migrant by means of naturalization through the marriage of the migrant with a French citizen. For details, see Le guide de l'entrée et du séjour des étrangers en France 1995.

6. Interview with Mohammad Changez and family at the family's residence, Sarcelles (7 February 2004). During the interview, the video recording of the engagement ceremony in Pakistan was shown with great pride by Ali's father, with special emphasis on his haveli in Rawalpindi (Pakistan) and the gifts presented to the bride.

7. This is strictly the case for Muslims in the quartier indien zone. It certainly should not be generalized for all South Asian Muslims in Paris.

8. Deobandi and Barelwi Muslims originate from the Deoband and Barelwi school of thought respectively. Both schools of thought had its origins in India, and exert a great influence on Muslims in the entire Indian subcontinent. 


\section{ABSTRACTS}

Miniya Chatterji, in the only article of this volume on France, examines how in Paris' so-called quartier indien, an area of intense migrant economic activity, community boundaries are being drawn among South Asian Muslims. She attempts to identify how 'sub-groups' are being redefined in migration, by tracing out the nature and depth of bonds and bridges shared by South Asian Muslims. She argues that, at such an early stage of settlement, economic activity seems more prevalent in defining these internal group boundaries than religion, national origin or language. 